\title{
Correction to: A psychophysiological investigation of mourning: There are two sides to the story
}

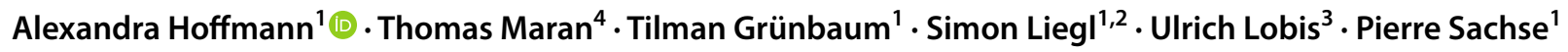

Published online: 2 March 2022

(c) The Author(s) 2022

\section{Correction to: Motivation and Emotion https://doi.org/10.1007/s11031-022-09928-3}

The original version of this article unfortunately contained a mistake. The corresponding author would like to correct the errors as given below:

(a) The corresponding author "Alexandra Hoffmann" affiliation should read as "Department of Psychology, University of Innsbruck, Innrain 52a, 6020 Innsbruck, Austria" instead of "Department of Psychology, Institute of Psychology, University of Innsbruck, Innrain 52a, 6020 Innsbruck, Austria".

(b) The co-author "Thomas Maran" affiliation should read as "Department of Strategic Management and Lead-

The original article can be found online at https://doi.org/10.1007/ s11031-022-09928-3.

Alexandra Hoffmann

alexandra.hoffmann@uibk.ac.at

Thomas Maran

thomas.k.maran@gmail.com

Tilman Grünbaum

tilman.gruenbaum@student.uibk.ac.at

Simon Liegl

simon.liegl@uni.li; simon.liegl@uibk.ac.at

Ulrich Lobis

ulrich.lobis@uibk.ac.at

Pierre Sachse

pierre.sachse@uibk.ac.at

1 Department of Psychology, University of Innsbruck, Innrain 52a, 6020 Innsbruck, Austria

2 Department of Entrepreneurship, University of Liechtenstein, Fürst-Franz-Josef-Straße, 9490 Vaduz, Liechtenstein

3 Research Institute Brenner-Archiv, University of Innsbruck, Josef-Hirn-Straße 5, 6020 Innsbruck, Austria

4 Department of Strategic Management and Leadership, University of Innsbruck, Innsbruck, Austria ership, University of Innsbruck, Innsbruck, Austria" instead of "Department of Psychology, University of Innsbruck, Innrain 52a, 6020 Innsbruck, Austria" and his email address should be thomas.k.maran@gmail. com instead of the institutional address of the University of Innsbruck.

The original article has been corrected.

Open Access This article is licensed under a Creative Commons Attribution 4.0 International License, which permits use, sharing, adaptation, distribution and reproduction in any medium or format, as long as you give appropriate credit to the original author(s) and the source, provide a link to the Creative Commons licence, and indicate if changes were made. The images or other third party material in this article are included in the article's Creative Commons licence, unless indicated otherwise in a credit line to the material. If material is not included in the article's Creative Commons licence and your intended use is not permitted by statutory regulation or exceeds the permitted use, you will need to obtain permission directly from the copyright holder. To view a copy of this licence, visit http://creativecommons.org/licenses/by/4.0/.

Publisher's Note Springer Nature remains neutral with regard to jurisdictional claims in published maps and institutional affiliations. 